\title{
Kinetics and Mechanism of the Redox Reaction of Naphthol Green B with Hydrazine Dihydrochloride in Aqueous Acidic Medium
}

\author{
B. Myek ${ }^{1, *}$, S. O. Idris ${ }^{2}$, J. F. Iyun ${ }^{2}$ \\ ${ }^{1}$ Department of Chemistry, Kaduna State University, Kaduna, Nigeria \\ ${ }^{2}$ Department of Chemistry, Ahmadu Bello University, Zaria, Nigeria
}

Email address:

myekbb@yahoo.com (B. Myek)

*Corresponding author

\section{To cite this article:}

B. Myek, S. O. Idris, J. F. Iyun. Kinetics and Mechanism of the Redox Reaction of Naphthol Green B with Hydrazine Dihydrochloride in Aqueous Acidic Medium. Science Journal of Chemistry. Vol. 5, No. 6, 2017, pp. 76-79. doi: 10.11648/j.sjc.20170506.11

Received: March 7, 2017; Accepted: March 18, 2017; Published: November 22, 2017

\begin{abstract}
The kinetics of the redox reaction between naphthol green B and hydrazine dihydrochloride has been studied in aqueous hydrochloric acid medium at an ionic strength, $\mathrm{I}=0.50 \mathrm{~mol} \mathrm{dm}{ }^{-3}(\mathrm{NaCl}),\left[\mathrm{H}^{+}\right]=1.0 \times 10^{-4} \mathrm{moldm}^{-3}(\mathrm{HCl})$ and $\mathrm{T}=$ $21 \pm 1^{\circ} \mathrm{C}$. The redox reaction displayed a stoichiometry of $1: 1$ and obeys the rate law: $-\mathrm{d}\left[\mathrm{NGB}^{3-}\right] / \mathrm{dt}=\mathrm{k}_{2}\left[\mathrm{NGB}^{3-}\right]\left[\mathrm{N}_{2} \mathrm{H}_{4} \cdot 2 \mathrm{HCl}\right]$. Change in hydrogen ion concentration of the reaction medium has no effect on the rate of the reaction. Added cations and anions inhibited the rate of the reaction. The redox reaction showed negative salt effect, with the rate decreasing with increase in ionic strength of the reaction medium. Results of the Michaelis-Menten's plot show that an intermediate complex was not formed during the course of the reaction. The outersphere mechanism is proposed for this reaction.
\end{abstract}

Keywords: Kinetic, Naphthol Green B, Redox, Hydrazine Dihydrochloride, Intermediate

\section{Introduction}

Naphthol green $\mathrm{B}\left(\mathrm{NGB}^{3-}\right)$ is used in the production of drugs, cosmetics and for staining purposes. It possesses excellent redox characteristic. A new amperometric glucose biosensor with naphthol green $\mathrm{B}$ as a mediatior has been reported [1]. It was found that naphthol green B is a good mediator, promoting electron transfer from glucose oxidase to graphite electrode.

Hydrazine dihydrochloride, which is a powerful reducing agent, has similarity to the thiourea by possessing nitrogen in its structure can also be possible inhibitor and similar compounds [2]. Hydrazine and its derivatives have been used in industry, agriculture and other fields, including photographic development, rocketry, explosives, and insecticides and blowing agents for plastics. Kinetic study of the oxidation of hydrazine dihydrochloride by aqueous iodine has been reported [3]. It was found that the reaction is first order in both reactants. Reduction of aqueous silver nitrate by hydrazine dihydrochloride in weakly alkaline solution results in a polydisperse colloid that is stable for many months without addition of any stabilizing compounds [4].

This work is carried out to further understand the reaction of naphthol green $\mathrm{B}$ and that of hydrazine dihydrochloride.

\section{Materials and Methods}

A1.0 $\times 10^{-3} \mathrm{~mol} \mathrm{dm}^{-3}$ stock solution of naphthol green $\mathrm{B}$ (Analar grade) was prepared by dissolving $0.02196 \mathrm{~g}$ in $25 \mathrm{~cm}^{3}$ flask using distilled water. Hydrazine dihydrochloride solution was prepared by dissolving known quantities in distilled water. $1.0 \mathrm{~mol} \mathrm{dm}^{-3}$ solution of hydrochloric acid (BDH) was prepared (36\%, specific gravity 1.18$)$ and was standardized titrimetrically. Sodium chloride was used to maintain constant ionic strength of the reaction.

The reaction stoichiometry was determined spectrophotometrically using the mole ratio method [5]. This was accomplished by measuring the absorbance of solutions containing varying concentrations of hydrazine

Dihydrochloride in the range $(0.08-1.40) \times 10^{-4} \mathrm{~mol} \mathrm{dm}^{-3}$, 
$\left[\mathrm{H}^{+}\right]=1.0 \times 10^{-4} \mathrm{~mol} \mathrm{dm}^{-3}$ and $\mathrm{I}=0.50 \mathrm{~mol} \mathrm{dm}^{-3}$ at $700 \mathrm{~nm}$, after the reaction had gone to completion by the observation of a steady zero absorbance value over a period of two days. A point of inflection on the curve of the absorbance versus mole ratio corresponds to the stoichiometry of the reaction.

The ionic strength of the reaction mixture was varied between 0.4 and $1.0 \mathrm{~mol} \mathrm{dm}^{-3}$. [ $\left.\mathrm{NGB}^{3-}\right],\left[\mathrm{N}_{2} \mathrm{H}_{4} \cdot 2 \mathrm{HCl}\right]$, and $\left[\mathrm{H}^{+}\right]$were maintained constant. Reaction temperature was maintained at $21 \pm 1^{\circ} \mathrm{C}$. Relationship of reaction rate with changes in the ionic strength was determined by plotting $\log k_{2}$ versus $I^{1 / 2}$.

The effect of changes in acid concentration on the reaction rate was investigated by keeping $\left[\mathrm{NGB}^{3-}\right]$ and $\left[\mathrm{N}_{2} \mathrm{H}_{4} \cdot 2 \mathrm{HCl}\right]$ constant while varying $\left[\mathrm{H}^{+}\right]$in the range $(0.10-20.0) \times 10^{-4}$ $\mathrm{mol} \mathrm{dm}{ }^{-3}$ at $21 \pm 1^{\circ} \mathrm{C}$ and $\mathrm{I}=0.50 \mathrm{~mol} \mathrm{dm}^{-3}$.

A 252 spectrophotometer Model was used to follow the decrease in absorbance of the dye at $700 \mathrm{~nm}, \mathrm{~T}=23 \pm 1^{\circ} \mathrm{C}, \mathrm{I}=$ $0.5 \mathrm{~mol} \mathrm{dm}^{-3}(\mathrm{NaCl})$, and $\left[\mathrm{H}^{+}\right]=1.0 \times 10^{-4} \mathrm{~mol} \mathrm{dm}^{-3}(\mathrm{HCl})$. All kinetic runs were performed under pseudo-first order conditions with $\left[\mathrm{NGB}^{3-}\right]$ at least 900 -fold in excess of $\left[\mathrm{N}_{2} \mathrm{H}_{4} \cdot 2 \mathrm{HCl}\right]$ at temperature of $21 \pm 1^{\circ} \mathrm{C}$, ionic strength of 0.50 mol dm${ }^{-3}(\mathrm{NaCl})$ and $\left[\mathrm{H}^{+}\right]=1.0 \times 10^{-4} \mathrm{~mol} \mathrm{dm}^{-3}(\mathrm{HCl})$. The pseudo-first order plots of $\log \left(\mathrm{A}_{\mathrm{t}}-\mathrm{A}_{\infty}\right)$ versus time were made and the slope of the plots gave the pseudo-first order rate constant, $\mathrm{k}_{1}$. The second order rate constants, $\mathrm{k}_{2}$ were determined from $\mathrm{k}_{1}$ as $\mathrm{k}_{1} /\left[\mathrm{N}_{2} \mathrm{H}_{4} \cdot 2 \mathrm{HCl}\right]$ [6].

The effect of added ions on the reaction rate was observed by addition of $(1-50) \times 10^{-3} \mathrm{~mol} \mathrm{dm}^{-3}$ of the ions $\left(\mathrm{Ca}^{2+}, \mathrm{Mg}^{2+}\right.$, $\mathrm{SO}_{4}^{2-}$ and $\mathrm{CH}_{3} \mathrm{COO}^{-}$), while the concentrations of naphthol green $\mathrm{B}$, the oxidant, hydrogen ion, temperature and ionic strength of reaction medium were kept constant.

Test for the presence of stable, detected intermediate formed during the course of the reaction was carried out spectrophotometrically. The electronic spectra of partially reacted reaction mixture (after one minute of mixing) were recorded at various time intervals depending on the speed of the reaction. A similar run was made for the dye alone in each case. This was carried out in order to determine whether there is significant shift in $\lambda_{\max }$ or enhacement of peak resulted as the reaction progressed.

\section{Results and Discussion}

The stoichiometric studies showed that one mole of naphthol green B was consumed by one mole of $\mathrm{N}_{2} \mathrm{H}_{4} \cdot 2 \mathrm{HCl}$. The overall stoichiometry equation is shown in equation (1).

$$
\mathrm{NGB}^{3-}+\mathrm{N}_{2} \mathrm{H}_{4} \cdot 2 \mathrm{HCl} \rightarrow \text { Products }
$$

Organic product of the reaction of $\mathrm{NGB}^{3-}$ with $\mathrm{N}_{2} \mathrm{H}_{4} \cdot 2 \mathrm{HCl}$ gave a yellow precipitate with 2, 4-dinitrophenylhydrazine, confirming the presence of carbonyl group. Ketone was further distinguished by the addition of acidified potassium dichromate, which does not change the colour of the reacting mixture.
The linearity of the pseudo-first order plots (Figure 1) suggests a first order dependence of reaction rate on $\left[\mathrm{NGB}^{3-}\right]$ and $\left[\mathrm{N}_{2} \mathrm{H}_{4} \cdot 2 \mathrm{HCl}\right]$ under the experimental conditions employed in this investigation. Similar first order dependence has been reported for the oxidation of hydrazine dihydrochloride by aqueous iodine [3]. The reaction is therefore second order overall at constant hydrogen ion concentration. This may be represented as:

$$
-\mathrm{d} / \mathrm{dt}=\mathrm{k}_{2}\left[\mathrm{NGB}^{3-}\right]\left[\mathrm{N}_{2} \mathrm{H}_{4} \cdot 2 \mathrm{HCl}\right]
$$

The rate of reaction showed lack of hydrogen ion concentration dependence in the range $(0.1-20) \times 10^{-4} \mathrm{~mol}$ $\mathrm{dm}^{-3}$. This independence is in accord with the fact that neither the oxidant nor the reductant undergoes significant protonation changes under the reaction conditions. Similar result has been reported [7]. The redox reaction showed negative salt effect, with the rate decreasing with increase in ionic strength from $0.4-1.0 \mathrm{~mol} \mathrm{dm} \mathrm{dm}^{-3}(\mathrm{NaCl})$. This observation of negative Bronsted-Debye salt indicates that species that formed the activated complex are of opposite charges. Plot of $\operatorname{logk}_{2}$ against $\mathrm{I}^{1 / 2}$ gave a slope of -1.26 $\left(\mathrm{R}^{2}=0.98\right)$. (Figure 2)

Lack of spectrophotometric evidence for the formation of intermediate complex suggests an outersphere mechanism. Michaelis-Mentein's plot of $1 / \mathrm{k}_{1}$ versus $1 /\left[\mathrm{N}_{2} \mathrm{H}_{4} \cdot 2 \mathrm{HCl}\right]$ (Figure 3) had an intercept, suggesting an innersphere. However, ions inhibition as shown in Table 2 and 3 is a characteristic of the outersphere mechanism [8]. This evidence suggests that this reaction is probably operating by the outersphere mechanism. On the basis of the above the following reaction scheme is proposed for this reaction.

$$
\begin{gathered}
\mathrm{N}_{2} \mathrm{H}_{4} \cdot 2 \mathrm{HCl}^{\mathrm{K}} \stackrel{\mathrm{K}_{1}}{\rightarrow} \mathrm{N}_{2} \mathrm{H}_{5}^{+}+\mathrm{H}^{+}+2 \mathrm{Cl}^{-} \\
\mathrm{NGB}^{3-}+\mathrm{N}_{2} \mathrm{H}_{5}^{+} \stackrel{\mathrm{K}_{2}}{\longrightarrow}\left[\mathrm{NGB}^{3-}, \mathrm{N}_{2} \mathrm{H}_{5}^{+}\right] \\
{\left[\mathrm{NGB}^{3-}, \mathrm{N}_{2} \mathrm{H}_{5}^{+}\right] \stackrel{\mathrm{k}_{3}}{\longrightarrow} \text { Products (slow) }} \\
\text { Rate }=\mathrm{k}_{3}\left[\mathrm{NGB}^{3-}, \mathrm{N}_{2} \mathrm{H}_{5}^{+}\right]
\end{gathered}
$$

From equation (4),

$$
\begin{gathered}
\mathrm{K}_{2}=\frac{\left[\mathrm{NGB}^{3-}, \mathrm{N}_{2} \mathrm{H}_{5}^{+}\right]}{\left[\mathrm{NGB}^{3-}\right]\left[\mathrm{N}_{2} \mathrm{H}_{5}^{+}\right]} \\
{\left[\mathrm{NGB}^{3-}, \mathrm{N}_{2} \mathrm{H}_{5}^{+}\right]=\mathrm{K}_{2}\left[\mathrm{NGB}^{3-}\right]\left[\mathrm{N}_{2} \mathrm{H}_{5}^{+}\right]}
\end{gathered}
$$

Substituting equation (8) into (6) gives

$$
\begin{aligned}
& \text { Rate }=\mathrm{k}_{3} \mathrm{~K}_{2}\left[\mathrm{NGB}^{3-}\right]\left[\mathrm{N}_{2} \mathrm{H}_{5}^{+}\right] \\
& \text {Rate }=\mathrm{k}^{\prime}\left[\mathrm{NGB}^{3-}\right]\left[\mathrm{N}_{2} \mathrm{H}_{5}^{+}\right]
\end{aligned}
$$

Where $\mathrm{k}_{3} \mathrm{~K}_{2}=\mathrm{k}$. 


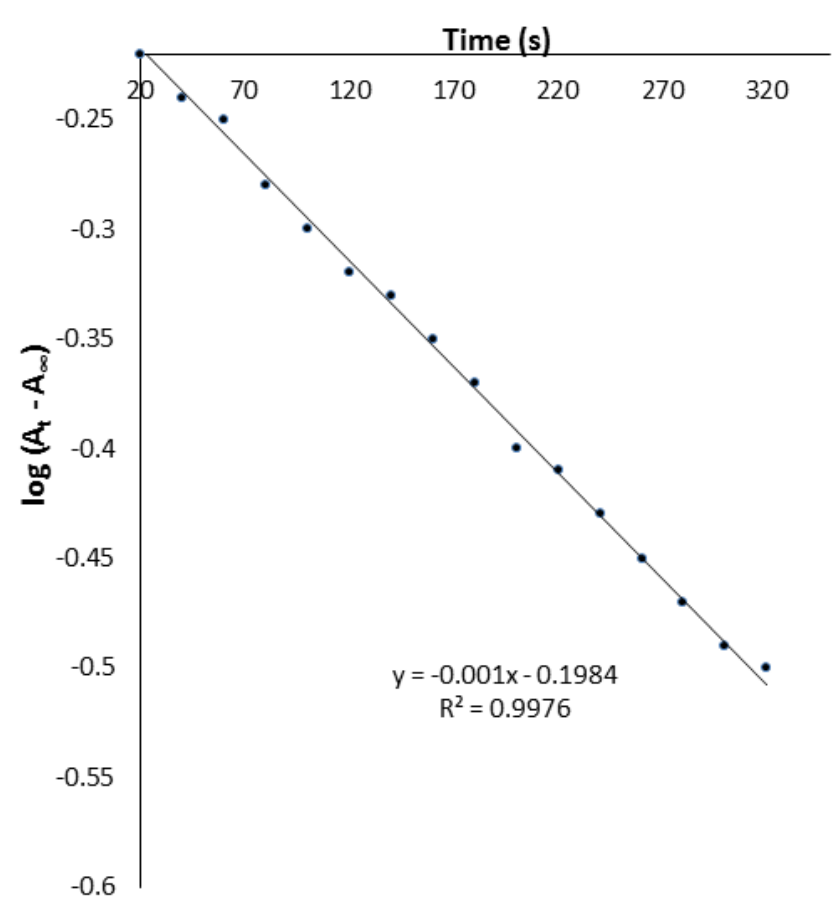

Figure 1. Typical pseudo-first order plot for the redox reaction of naphthol green $B$ with $\mathrm{N}_{2} \mathrm{H}_{4} .2 \mathrm{HCl}$ at $\left[\mathrm{NGB}^{3-}\right]=4.0 \times 10^{-5} \mathrm{~mol} \mathrm{dm}^{-3}$, $\left[\mathrm{N}_{2} \mathrm{H}_{4} .2 \mathrm{HCl}\right]=20.0 \times 10^{-2} \mathrm{~mol} \mathrm{dm}^{-3},\left[\mathrm{H}^{+}\right]=1.0 \times 10^{-4} \mathrm{~mol} \mathrm{dm}^{-3}, I=0.50 \mathrm{~mol} \mathrm{dm} m^{-3}$, $\lambda=700 \mathrm{~nm}$ and $T=21 \pm 1^{\circ} \mathrm{C}$.

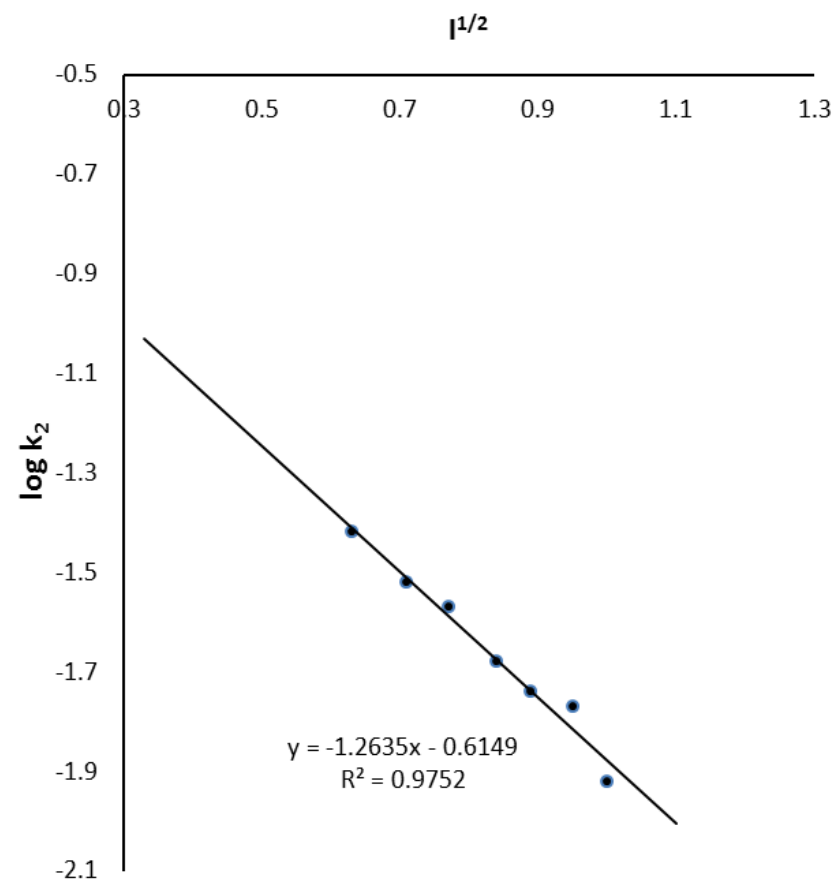

Figure 2. Plot of $\log k_{2}$ versus $I^{1 / 2}$ for the redox reaction between naphthol green $\mathrm{B}$ and $\mathrm{N}_{2} \mathrm{H}_{4} . \quad 2 \mathrm{HCl}$ at $\left[\mathrm{NGB}^{3-}\right]=4.0 \times 10^{-5} \mathrm{~mol} \mathrm{dm}^{-3}$, $\left[\mathrm{N}_{2} \mathrm{H}_{4} .2 \mathrm{HCl}\right]=20.0 \times 10^{-2} \mathrm{~mol} \mathrm{dm}^{-3},\left[\mathrm{H}^{+}\right]=1.0 \times 10^{-4} \mathrm{~mol} \mathrm{dm}^{-3}, I=0.4-1.0 \mathrm{~mol}$ $\mathrm{dm}^{-3}, \lambda=700 \mathrm{~nm}$ and $T=21 \pm 1^{\circ} \mathrm{C}$

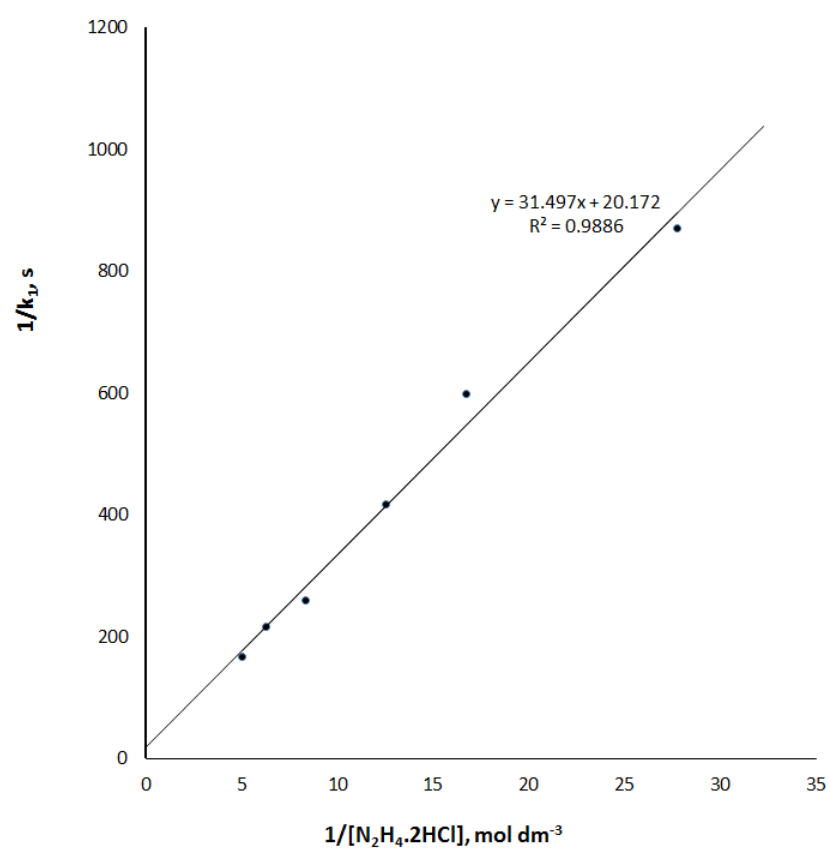

Figure 3. Michaelis-Menten's plot for the redox reaction between naphthol green $\mathrm{B}$ and $\mathrm{N}_{2} \mathrm{H}_{4} .2 \mathrm{HCl}$ at $\left[\mathrm{NGB}^{3-}\right]=4.0 \times 10^{-5} \mathrm{~mol} \mathrm{dm}^{-3}$, $\left[\mathrm{N}_{2} \mathrm{H}_{4} .2 \mathrm{HCl}\right]=(3.6-$ 20.0) $\times 10^{-2} \mathrm{~mol} \mathrm{dm}^{-3},\left[\mathrm{H}^{+}\right]=1.0 \times 10^{-4} \mathrm{~mol} \mathrm{dm^{-3 }}, I=0.50 \mathrm{~mol} \mathrm{dm} \mathrm{m}^{-3}, \lambda=700 \mathrm{~nm}$ and $T 21 \pm 1{ }^{\circ} \mathrm{C}$

Table 1. Pseudo-first order and second order rate constants for the reaction of naphthol green $\mathrm{B}$ and $\mathrm{N}_{2} \mathrm{H}_{4} .2 \mathrm{HCl}$ at $\left[\mathrm{NGB}^{3-}\right]=4.0 \times 10^{-5} \mathrm{~mol} \mathrm{dm}^{-3}, \lambda=700$ nm and $T=21 \pm 1^{\circ} \mathrm{C}$.

\begin{tabular}{lllll}
\hline $\begin{array}{l}\mathbf{1 0} \\
\left.\mathbf{m o l} \mathbf{~ d m}_{\mathbf{2}} \mathbf{H}_{\mathbf{4}} \mathbf{. 2} \mathbf{H C l}\right],\end{array}$ & $\begin{array}{l}\mathbf{1 0 ^ { 4 }}\left[\mathbf{H}^{+}\right], \mathbf{m o l} \\
\mathbf{d m}^{-3}\end{array}$ & $\begin{array}{l}\mathbf{1 0} \mathbf{1} \mathbf{I}, \mathbf{m o l} \\
\mathbf{d m}^{-3}\end{array}$ & $\mathbf{1 0}^{3} \mathbf{k}_{\mathbf{1}}, \mathbf{s}^{-\mathbf{1}}$ & $\begin{array}{l}\mathbf{k}_{\mathbf{2}}, \mathbf{d m}^{\mathbf{3}} \\
\mathbf{m o l}^{-1} \mathbf{s}^{-1}\end{array}$ \\
\hline 3.6 & 1.0 & 5.0 & 1.15 & 0.032 \\
6.0 & 1.0 & 5.0 & 1.67 & 0.029 \\
8.0 & 1.0 & 5.0 & 2.39 & 0.030 \\
12.0 & 1.0 & 5.0 & 3.85 & 0.032 \\
16.0 & 1.0 & 5.0 & 4.61 & 0.029 \\
20.0 & 1.0 & 5.0 & 5.95 & 0.030 \\
20.0 & 0.1 & 5.0 & 5.37 & 0.027 \\
20.0 & 0.5 & 5.0 & 5.78 & 0.029 \\
20.0 & 1.0 & 5.0 & 5.76 & 0.029 \\
20.0 & 1.5 & 5.0 & 5.94 & 0.030 \\
20.0 & 4.0 & 5.0 & 6.08 & 0.030 \\
20.0 & 5.0 & 5.0 & 6.20 & 0.031 \\
20.0 & 20.0 & 5.0 & 6.03 & 0.030 \\
20.0 & 1.0 & 4.0 & 7.60 & 0.038 \\
20.0 & 1.0 & 5.0 & 5.94 & 0.030 \\
20.0 & 1.0 & 6.0 & 5.37 & 0.027 \\
20.0 & 1.0 & 7.0 & 4.21 & 0.021 \\
20.0 & 1.0 & 8.0 & 3.55 & 0.018 \\
20.0 & 1.0 & 9.0 & 3.45 & 0.017 \\
20.0 & 1.0 & 10.0 & 2.30 & 0.012 \\
\hline & & & & \\
\hline
\end{tabular}


Table 2. Rate data for the effect of added cations $\left(\mathrm{Ca}^{2+}\right.$ and $\left.\mathrm{Mg}^{2+}\right)$ on the rate of reaction of naphthol green $\mathrm{B}$ with $\mathrm{N}_{2} \mathrm{H}_{4} .2 \mathrm{HCl}$ a $t\left[\mathrm{NGB}^{3-}\right]=4.0 \times 10^{-5} \mathrm{~mol}$ $d^{-3},\left[N_{2} H_{4} .2 \mathrm{HCl}\right]=20.0 \times 10^{-2} \mathrm{moldm}^{-3},\left[\mathrm{H}^{+}\right]=1.0 \times 10^{-4} \mathrm{moldm}^{-3}, \quad I=0.50 \mathrm{~mol}$ $\mathrm{dm}^{-3}, \lambda=700 \mathrm{~nm}$ and $T=21 \pm 1^{\circ} \mathrm{C}$.

\begin{tabular}{llll}
\hline Ion & $\mathbf{1 0}^{\mathbf{3}}[\mathbf{i o n}], \mathbf{~ m o l ~} \mathbf{~ d m}^{-3}$ & $\mathbf{1 0}^{\mathbf{3}} \mathbf{k}_{\mathbf{1}}, \mathbf{s}^{\mathbf{- 1}}$ & $\mathbf{k}_{\mathbf{2}}, \mathbf{d m}^{\mathbf{3}} \mathbf{~ m o l}^{\mathbf{- 1}} \mathbf{s}^{\mathbf{- 1}}$ \\
\hline & 1.0 & 4.19 & 0.021 \\
$\mathrm{Ca}^{2+}$ & 5.0 & 3.62 & 0.018 \\
& 10.0 & 3.07 & 0.015 \\
& 20.0 & 2.79 & 0.014 \\
& 30.0 & 2.46 & 0.012 \\
& 1.0 & 4.45 & 0.022 \\
& 5.0 & 3.53 & 0.018 \\
$\mathrm{Mg}^{2+}$ & 10.0 & 3.13 & 0.016 \\
& 20.0 & 2.56 & 0.013 \\
& 30.0 & 2.06 & 0.010 \\
\hline
\end{tabular}

Table 3. Rate data for the effect of added anions ( $\mathrm{SO}_{4}{ }^{2-}$ and $\mathrm{CH}_{3} \mathrm{COO}$ ) on the rate of reaction of naphthol green $\mathrm{B}$ with $\mathrm{N}_{2} \mathrm{~N}_{4} .2 \mathrm{HCl}$ at $\left[\mathrm{NGB}^{3-}\right]$ $=4.0 \times 10^{-5} \mathrm{~mol} \mathrm{dm} m^{-3},\left[N_{2} \mathrm{~N}_{4} .2 \mathrm{HCl}\right]=20.0 \times 10^{-2} \mathrm{~mol} \mathrm{dm}^{-3},\left[\mathrm{H}^{+}\right]=1.010^{-4} \mathrm{~mol}$ $\mathrm{dm}^{-3}, I=0.50 \mathrm{~mol} \mathrm{dm}{ }^{-3}, \lambda=700 \mathrm{~nm}$ and $T=21 \pm 1^{\circ} \mathrm{C}$.

\begin{tabular}{clll}
\hline Ion & $\mathbf{1 0}^{\mathbf{3}}[\mathbf{i o n}], \mathbf{~ m o l d m}^{-\mathbf{3}}$ & $\mathbf{1 0}^{\mathbf{3}} \mathbf{k}_{\mathbf{1}}, \mathbf{s}^{\mathbf{- 1}}$ & $\mathbf{k}_{\mathbf{2}}, \mathbf{d m}^{\mathbf{3}} \mathbf{m o l}^{-\mathbf{1}} \mathbf{s}^{-\mathbf{1}}$ \\
\hline & 1.0 & 4.26 & 0.021 \\
& 5.0 & 3.45 & 0.017 \\
$\mathrm{SO}_{4}{ }^{2-}$ & 10.0 & 3.19 & 0.016 \\
& 20.0 & 2.86 & 0.014 \\
& 30.0 & 2.44 & 0.012 \\
& 1.0 & 4.42 & 0.022 \\
& 10.0 & 3.54 & 0.018 \\
$\mathrm{CH}_{3} \mathrm{COO}^{-}$ & 20.0 & 3.13 & 0.016 \\
& 30.0 & 2.80 & 0.014 \\
& 40.0 & 2.30 & 0.012 \\
& 50.0 & 2.18 & 0.011 \\
\hline
\end{tabular}

\section{Conclusion}

The redox reaction of naphthol green $B$ and hydrazine dihydrochloride in acidic medium showed a stoichiometry of $1: 1$, a first order was observed for $\mathrm{NGB}^{3-}$ and $\left[\mathrm{N}_{2} \mathrm{H}_{4} \cdot 2 \mathrm{HCl}\right]$. The rate of reaction had no effects with increase in acid concentration. Increase in ionic strength decreases the rate of the reaction. Added ions inhibited the rate of the reaction. An intermediate complex was not implicated during the course of the reaction. Based on the above results, it is proposed that the reaction is most probably operates through the outersphere mechanism.

\section{References}

[1] Zhao, Q., Yuan, R., Chang, L. M., Chai, Y. Q., Zhong, X. (2004). A new amperometric glucose biosensor with naphthol green B as mediator. Chinesechem. let. Vol. 5, No. 2, pp 208 211.

[2] Cao, Y. I., Jiang, X. M., Kareem, A., Dou, Z. H., Rakeman, M. A., Zhan, M. L., Dulong, G. R. (1994). Iodination of irrigation waters as a method of supplying iodine to a severally iodine deficient population in Xinjing, China. The lancet, (344): 107109.

[3] Mshelia, M. S., Iyun, J. F., Uzairu, A., Idris, S. (2010). Kinetics and mechanism of the oxidation of hydrazine dihydrochloride by aqueous iodine. J. Am. Sci. 6(9).

[4] Ulrich, N., Amelie, Z. C., Karin, P., Siegfried, S. (2000). Reduction of aqueous silver nitrate by hydrazine dihydrochloride. J. Am. Chem. Soc. 16(23), pp 9087-9091.

[5] Yusuf, U. F., J. F. Iyun and G. A. Ayoko, 2004. Oxidation of hypophosphorus acid by poly pyridineiron (III) complexes. Chem. Class. J. 118-122.

[6] Mohammed, Y., Iyun, J. F., Idris, S. O. (2009). Kinetic approach to the mechanism of the redox reaction of malachite green and permanganate ion in aqueous acidic medium. Afr. $J$. Pureand A ppl. Chem, 3: 12, 269.

[7] Rao, K. V., Rao, J. K., Sivaswaroop, P and Kumar, A. K (1987). Kinetic of stepwise oxidation of manganese (II) by $\mathrm{S}_{2} \mathrm{O}_{8}{ }^{2-}$ in phosphoric acid medium. Trans. Met. Chem., 12: 442-448.

[8] Przystas, T. J. and Sutin, N. (1973). Kinetic studies of anion assisted outersphere electron transfer reactions. J. Am. Chem. Soc., 95, 5545. 23: 27-35. 